\title{
IC) IN SILICO ANALYSIS OF MEMBER OF CTR FAMILY AND COPPER DEPENDENT TRANSCRIPTIONS FACTOR IN Paracoccidioides spp. \\ PETITO, G1,2; PETITO, A.D.C1.
}

1-Department of pharmacy and nursing of Uni-Anhanguera, Goiânia-GO, Brazil; 2- Genetic and Molecular Biology Program, UFG, Brazil

E-mail: guilherme.petito@hotmail.com

\section{INTRODUCTION}

Copper is an essential cofactor for many enzymes that act on important metabolic processes in microorganisms, such as Paracoccidioides spp. The perfect balance of copper inside fungal cell is very important for survive, growth an virulence of that pathogen. The aim of this study was to find the sequence homology in Paracoccidioides lutzzi (isolate Pb01) and Paracoccidioides brasiliensis (isolate $\mathrm{Pb} 18$ ) with member of CTR family proteins and copper dependent transcription factor CUF1 as well as ACE1 and MAC1, and make a detailed structural and functional analysis between them.

\section{MATERIALS AND METHODS}

The study data were obtained by an analysis in silico using tools like BLAST (Basic Local Alignment Search toll), InterPro (Protein Sequence analysis and classification), Clustalx and I-Tasser. Was used sequence of Aspergillus nidulans (taxid:162425) and/or Saccharomyces cerevisiae (taxid:559292) how model for search homology sequence of CTR Family, Ace1 and Mac1 transcription fator on Paracoccidioides lutzzi (Pb01) (taxid:502779) and Paracoccidioides brasiliensis (Pb18) (taxid:502780). Table and figures were used to show the results, as well as statistics data (e-value, ID, others).

\section{RESULTS}

Table 1. Structural comparison between CTR3 protein in Saccharomyces cerevisiae and putative proteins in Pb01 (PAAG_05251) and Pb18 (PADG_05084).

\begin{tabular}{c|ccc} 
Estrutura & $\begin{array}{c}\text { CTR3 } \\
\text { S. cerevisiae }\end{array}$ & $\begin{array}{c}\text { CTR } \\
\text { Pb01 }\end{array}$ & $\begin{array}{c}\text { CTR } \\
\text { Pb18 }\end{array}$ \\
\hline $\begin{array}{c}\text { Presence of 03 transmembrane } \\
\text { domains (TDM) }\end{array}$ & Present & Present & Present \\
$\begin{array}{c}\text { Presence of one metionine 20 aa } \\
\text { upstream at the TDM1 } \\
\text { \% of cysteine }\end{array}$ & Present & Present & Present \\
Mets motif upstream at the TDM1 & None & MXXM & $\begin{array}{c}\text { MXXMXXM } \\
\text { Upstream TDM1 }\end{array}$ \\
& & Upstream TDM1 & \\
Mets motif on TDM2 & MLLFM & MLLAM & MLLAM \\
No of aa & 241 & 179 & 182 \\
\hline
\end{tabular}

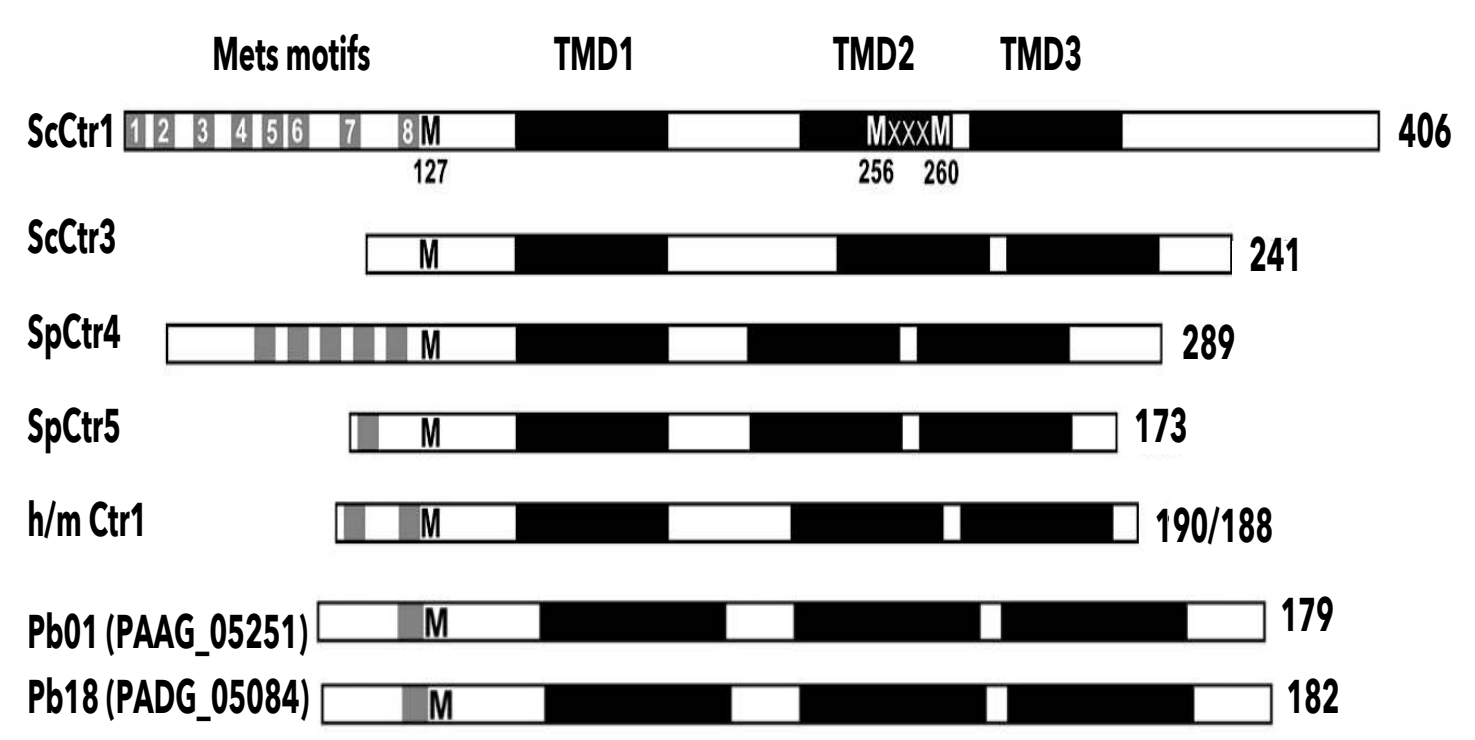

Figure 1. Comparasion between the primary structure model of CTR high affinity copper transport proteins proposed for CTR (CTR1, CTR3, CTR4 and CTR5) family in Saccharomyces cerevisiae (Sc), Schizosaccharomyces pombe (Sp) and human/mouse $(\mathrm{h} / \mathrm{m})$ and the model proposed for Pb01 and $\mathrm{Pb} 18$ after in silico analysis.

\section{A}
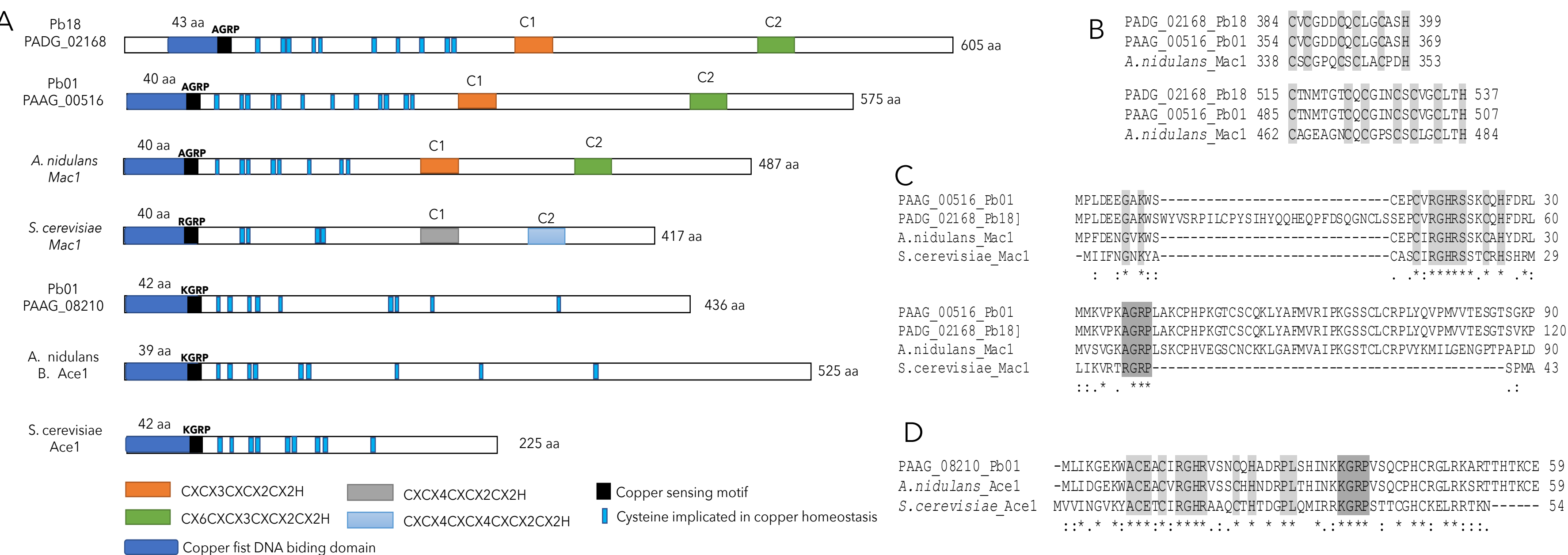

D

Figure 2. A. Compararion between the primary sequence structure model for trancription fator Mac1/Ace1 from Aspergillus nidulans (XP_658262/CBF85835.1) and Saccharomyces cerevisiae (NP_013734/NP_011349) with the putative sequence found on Pb01 and Pb18. B. Cysteine rich motifs $\mathrm{C} 1$ and $\mathrm{C} 2$ on Pb01 (PAAG_00516), Pb18 (PADG_02168) and Aspergillus nidulans (Xp_658262). C. Copper-fist-DNA-biding domains on Pb01 (PAAG_00516), Pb18 (PADG_02168), Aspergillus nidulans (XP_658262) and Saccharomyces cerevisiae (NP_013734). D. Copper-fist-DNA-biding domains on Pb18 (PADG_02168), Aspergillus nidulans (CBF85835.1) and Saccharomyces cerevisiae (NP_011349).

\section{CONCLUSION}

Putative sequences were found for CTR3 on Pb01 (PAAG_05251) and Pb18 (PADG_05084) with all features necessary for a CTR protein family. Still, putative sequences for transcription factor Mac1 were found on both isolates, being PAAG_00516 for Pb01 and PADG_02168 for Pb18. However, for transcription factor Ace1, only one sequence reveled homology, being present on Pb01 (PAAG_08210). 